\title{
MYCOTIC KERATITIS
}

\author{
Lt Col S GOKHALE*, Dr S JOSHI+, \\ Maj KTS HAIDER+, Col VC OHRI\#, \\ Col M DESHPANDE, VSM**
}

\begin{abstract}
Mycotic keratitis is a distressing infection and may lead to permanent blindness. Fifty two cases of suspected mycotic keratitis were studied from Jan 91 to Sep 94. Specimens were collected on swabs in 20 cases and by corneal scraping in 32 cases. Wet mount examination of the specimens revealed fungal elements in $8(15.4 \%)$ cases, of which 3 specimens were collected on swabs and 5 by corneal scraping. Fungi were isolated from a total of $12(23.1 \%)$ specimens 5 of which were obtained by swabs while 7 by corneal scraping. Important pathogens were Fusarium spp, Aspergillus spp, Candida albicans and Cephalosporium spp. Direct examination of the specimens was found to be less sensitive than culture for the diagnosis of mycotic keratitis.
\end{abstract}

MJAFI 1995; $51: 267-269$

KEY WORDS : Eye infection fungal; Keratitis; Laboratory diagnosis.

Introduction

$\mathbf{M}$ ycotic keratitis may develop subsequent to corneal trauma by vegetable or soil matter or due to contamination of a preexisting corneal ulcer by saprophytic fungi. Ocular surgery and use of contact lenses also increase the chance of fungal keratitis [1,2], The aetiological agents are commonly introduced from an exogenous source and most are normally saprophytic fungi. Some pathogenic fungi like Histoplasma capsulatum have also been known to cause primary keratomycosis [2]. Injudicious use of topical corticosteroids and antibacterial agents enhance the risk of mycotic keratitis. The management of mycotic keratitis poses a challenge to the ophthalmologist. Various techniques have contributed to early diagnosis of mycotic keratitis. Isolation of the fungus by culture is the most definitive criterion. The aim of this study was to determine the common agents responsible for mycotic keratitis in this part of the country and to evaluate the techniques of specimen collection.

\section{Material and Methods}

Clinically suspected cases of mycotic keratitis formed the subjects of this study. Specimens were obtained from 52 such cases. The cornea was anaesthetized with $4 \%$ xylocaine drops. Charcoal-coated cotton swabs were used for collection of material from 20 patients while scrapings from the cornea were obtained in 32 cases. Specimens were examined for fungal elements under $10 \% \mathrm{KOH}$ as wet preparations. The samples were also inoculated on Sabouraud's Dextrose Agar (SDA) for culture of fungi and on sheep blood agar for bacteria. Standard methods were used for identification of the organisms.

\section{Results}

Fifty two cases were investigated. Most of the patients belonged to the low socioeconomic group. Commonly affected age group was 21-40 years and the male to female ratio was $3: 1$ (Table 1). All patients gave history of trauma, mostly while working in farms and gardens.

Wet mount examination of the samples

*Reader, +Post Graduate Student, \#Prof and Head, Dept of Microbiology, * *Prof and Head, Dept of Ophthalmology, Armed Forces Medical College, Punc, 411040 
revealed fungal elements in $8(15.4 \%)$ cases, of which 3 specimens had been collected on swabs while 5 were corneal scrapings. On culture, fungi were grown from 12 specimens $(23.1 \%)$ out of 52 . Of these, 5 samples had been obtained on swabs and 7 by corneal scraping (Table 2). These 12 specimens included the 8 where fungal elements had already been observed on microscopy. Variety of agents were isolated, Fusarium spp and Aspergillus spp being the commonest (Table 3).

TABLE 1

Distribution of cases by age and sex

\begin{tabular}{lrrrrr}
\hline Age in years & \multicolumn{3}{c}{ Sex } & \multicolumn{2}{c}{ Total } \\
& \multicolumn{2}{c}{ Mnle } & \multicolumn{2}{c}{ Fernale } & \\
& No & $(\%)$ & No & $(\%)$ & No (\%) \\
\hline $0-10$ & \multicolumn{2}{c}{-} & & - & - \\
$11-20$ & & - & & - & - \\
$21-20$ & 20 & $(38.5)$ & 4 & $(7.7)$ & $24(46.2)$ \\
$31-40$ & 15 & $(28.8)$ & 6 & $(11.5)$ & $21(40.4)$ \\
$41 \&$ above & 4 & $(7.7)$ & 3 & $(5.8)$ & $7(13.5)$ \\
\hline Tolal & 39 & $(75.0)$ & 13 & $(25.0)$ & $52(100.0)$ \\
\hline
\end{tabular}

TABLE 2

Direct micrascopy and culture

\begin{tabular}{|c|c|c|c|c|}
\hline $\begin{array}{l}\text { Method of collection } \\
\text { of specimen }\end{array}$ & No & $\begin{array}{l}\text { Direct } \\
\text { microscopy } \\
\text { positive }\end{array}$ & & $\begin{array}{l}\text { Culture } \\
\text { positive }\end{array}$ \\
\hline Swabs & 20 & $3(15.0)$ & 5 & $(25.0)$ \\
\hline Scrapings & 32 & $5 \quad(15.6)$ & 7 & (21.9) \\
\hline Total & 52 & $8(15.4)$ & 12 & $(23.1)$ \\
\hline
\end{tabular}

Figures in parenthoses are percentages.

TABLE 3

Fungal isolates

\begin{tabular}{|c|c|}
\hline Name of the organism & No. $(\%)$ \\
\hline Fusarium spp & $4 \quad(33.3)$ \\
\hline Aspergillus spp & $3(25.0)$ \\
\hline Candida albicans & $2(16.7)$ \\
\hline Cephalosporium spp & $1 \quad[8.3]$ \\
\hline Unidentified & $2(16.7)$ \\
\hline Total & $12(100.0)$ \\
\hline
\end{tabular}

\section{Discussion}

Aetiological diagnosis of mycotic keratitis is essential for specific treatment. Demonstration of fungal elements and isolation of the agent are the available methods. All our patients had history of direct trauma, usually while working in fields. In one case, the injury was sustained by foreign body entering the eye while riding a two-wheeler. This patient did not use glasses or a helmet with visor which could have prevented such injury. Males in the age group 21 - 40 years were found to be most vulnerable probably due to their out-door activities and susceptibility to trauma. Variation in prevalence of mycotic keratitis in males and females depending on local socioeconomic conditions has been recorded [1,3,4]. In our study, males were found to suffer three times more than females.

Corneal scrapings have been considered as the ideal method of obtaining specimens. Collection of proper corneal scrapings requires skill and practice but this can be casily acquired. Upadhyay et al [1] had collected corneal scrapings without topical anaesthesia but were required to administer ketamine for general anaesthesia in children. We found topical anaesthesia with $4 \%$ xylocaine drops very satisfactory. Patwardhan et al [5] practiced bedside inoculation of the culture media. In our study, since the patients were ambulatory, all corneal scrapings were taken in the laboratory by the microbiologists with the help of an ophthalmologist. Collection of specimens in the laboratory has the obvious advantages of minimising contamination as well as eliminating transportation time. We have found that a properly collected swab is also a useful method of specimen collection, simplicity being its asset. Diagnosis is established early when direct microscopy reveals fungal elements, but microscopy is less sensitive than culture as the quantity of material obtained by scraping is limited and the fungi remain entangled in the cotton if the specimen is obtained on a swab.

Saprophytic fungi are the commonest agents of mycotic keratitis as they gain entry 
following trauma [2]. Aspergillus spp have been the commonest isolate from various part of India, followed by Acremonium spp, Fusarium spp and Candida spp [3-6]. In this study as well, Fusarium spp and Aspergillus spp were the commonest isolates.

Mycotic keratitis is a common and important ophthalmic infection. Early and proper diagnosis is important for adequate treatment. Corneal scrapings are not found to be superior to swabs for obtaining the specimens. Swabs, when collected properly, can also be usefully cultured for isolation of the fungus. Ease and simplicity are the obvious advantages. Culture is a more sensitive method than direct micoscopy though it takes longer to isolate the fungus. Judicious use of direct microscopy and culture is essential for early as well as specific diagnosis of mycotic keratitis.

\section{REFERENCES}

1. Upadhyay MP, Karmachary P'CD, Koirala S, Tuladhar NR, Bryan LE, Smolin G, Whitcher JP. Epidemiologic characteristics, prodisposing factors and etiological diagnosis of corneal ulceration in Nepal. Am J Ophthalmol 1991; 11 : 92-9.

2. Rippon JW. Pseudoallescheriasis. In : Medical Mycology - The pathogenic fungi and the pathogenic Actinomyces. 3rd ed. Philadelphia : WB Saunders, 1988; 666-8.

3. Pankaja Lakshmi, Vonugopal V. Tara Lakshmi, Vonugupal V, Gomathi A, Ramakrishna ES, Ilavarasi S. Mycotic keratitis in Madras. Indian / 1'athol Microbiol 1989; 32 : 190-7.

4. Chander J, Chakraluarti A, Sharma A, Saini JS. Mycotic keratitis - A five year sturly from Chandigarh. Ind J Med Microbiol 1993; $11: 218-22$.

5. Patwardhan NS, Damle AS, Bansal MI'. Isolation of Fusurium from corneal ulcers - case reports. Ind J Med Microbiol 1991; 9 : 234-6.

6. Haldar KK, Banerjec AR, Chakrabarti AK, Basak S. Primary mycotic keratitis among tea garden worktrs. Ind J Med Microbiul 1992; $10: 38-42$. 